\title{
Abdominal disturbances in children with Covid-19
}

\author{
Ferizat Dika-Haxhirexha ${ }^{1,2^{*}}$, Sevdije Koxha ${ }^{2}$, Ledia Qatipi ${ }^{2}$ \\ Shqiponja Turkeshi², Aulona Haxhirexha ${ }^{3}$
}

Received: 05 June 2021 / Accepted: 23 June 2021 / Published online: 20 July 2021

This article is published with open access at https://journal.astes.org.al

(C) The author(s) 2021. \& Copyright (C) 2021, the Albanian Society for Trauma and Emergency Surgery

(c) The Albanian Journal of Trauma and Emergency Surgery is an Open Access Journal. All articles are distributed under the terms of the Creative Commons Attribution Non-Commercial License: http://creativecommons.org/licenses/by-nc/4.0/) which permits unrestricted non-commercial use, distribution, and reproduction in any medium provided the original work is properly cited.

\section{Abstract}

Covid-19 continues to spread at an unprecedented pace, sparing no country in the world and including almost all ages. Although at the beginning of the pandemic, it was thought that the virus did not affect children, however over time, in different countries, more and more cases of children with Covid-19 begun to appear, though rarely among them were recorded any victims.

However, the clinical picture of infections with this virus in children was much more challenging than in adults.

In this article, we will present the case of three children of ages 4 to 14 years, with signs of acute abdomen, respectively with acute abdominal pain, fever, vomiting, and in whom acute appendicitis was suspected. In all three patients, anamnestic data showed positive family members infected with covid-19.

All three children were sent to the surgery ward for follow-up and further treatment.

The laboratory analyzes in all of them resulted in increased values of both erythrocyte sediment and CRP, while only in one of them the values of LDH and transaminases (AST, ALT) were also increased.

Ultrasonographic examination of the abdomen in two children showed the presence of a small amount of free fluid in the abdomen and mesentery thickening with several packets of enlarged lymph nodes. Radiography of the lungs did not show pulmonary lesions in any of the children. Body temperature ranged from 37.2 to $38.50 \mathrm{C}$, while urine was within the normal range.

All children were hospitalized and kept under observation for several consecutive days. At the same time, they were treated with antibiotics of the group of cephalosporins of the third generation, as well as with antipyretics (paracetamol).

As their condition improved and the abdominal pain subsided completely, they were released from the hospital with instructions to continue the rest and taking vitamins at home in the form of ready-made preparations for children.

Conclusion: While the Covid-19 pandemic is rapidly spreading and not sparing even children, pediatricians and surgeons must be very cautious in treating children with acute abdominal pain since infections with Covid-19, and not surgical diseases, might be the real cause of these concerns.

Key words: COVID-19, children, abdominal pain

Original article, no submission or publication in advance or in parallel

\section{* Corresponding author:}

Ferizate Dika - Haxhirexha MD. MSc. Ph.D.

$\bowtie$ ferizata@yahoo.com

1 The State University of Tetova, Faculty of Medicine, Republic of North MACEDONIA

2 PHO “Alba-Med" - Diber, Regional Hospital-Diber, Republic of North MACEDONIA.

3 Department of Burns and Plastic Surgery, University Hospital Center "Mother Teresa", Tirana, ALBANIA

\section{Introduction:}

Of the three children included in this article, two of them were boys and one girl. None of the children had anamnestic data of any health problems in the last month. Abdominal discomfort had started the day before, with a slight pain mainly in the upper quadrants, to spread then to the lower quadrants. Upon admission to our service the children were pale, tired, and dehydrated. Two of them were subfebrile, while the third patient was with high temperature of $38.6^{\circ}$ C. All three children complained of diffuse abdominal pain 
but with greater intensity and sensitivity in the lower right quadrant. Two (one aged 10 and the other 14 years old) of the children had also some episodes of vomiting. It is important to note that in all three families of children, there were members who had contact with persons infected with COVID-19.

During lung auscultation, no abnormal respiratory sounds or whistling were not heard in any of the children. While during abdominal palpation a pronounced tenderness was noticed especially in the lower parts of the abdomen. Lung radiography in children 4 and 10 years old resulted normal, whereas at 14 years ones the ground glass opacity at the lower zones of the right lung was seen.

Through abdominal auscultation an increased intestinal peristalsis was recorded in all three children. Laboratory tests including a complete examination of blood and urine, determination of enzymes such as LDH, AST and ALT, determination of erythrocyte sediment and CRP level were performed on all three children. Only one of them (14 years old) had increased leukocyte count, while in the other two they were within normal limits. CRP values were found to be increased in all three children. Ultrasound examination of the abdomen showed the presence of a free amount of fluid between the intestines and in the abdominal space.

In children, aged 14 years, the ultrasonographic examination showed slightly swollen appendix, while simultaneously the presence of a free abdominal fluid as well as enlargement of the mesenteric lymph nodes was recorded in all children.

All three children were sent to the surgical ward, to be evaluated by a surgeon.

The PCR test was performed only in 14-year-old boys and resulted negative. All the children were treated in a surgical ward for two to three days, and none of them underwent surgery. They were treated with antibiotics, vitamins and analgesics. The general condition of the children was gradually improved, and they were sent for home treatment. Six weeks later, the antibodies to COVID-19 in the blood was determined, which resulted positive in all three children.

\section{Discussion:}

The most important way to fight this viral infection is to detect COVID-19 early, isolate cases, trace contacts and deliver the correct information to the general public [1]

Gastrointestinal involvement, such as abdominal pain, nausea, vomiting and diarrhoea, has been recently reported in the literature[2], Diarrhoea occurs secondary to the interaction between ACE2, highly expressed in the human small intestine, and 2019-nCoV cell entry receptor ACE2. Recent studies show that 2019-nCoV RNA has been detected in stool samples, confirming faecal-oral transmission. According to the literature, the incidence of diarrhoea could be underestimated:[3]
Diagnosing the causes of acute abdominal pain in children is often a real challenge, but diagnosing the cause of acute abdomen at the time of the Covid-19 pandemic, makes it even more difficult to establish an accurate diagnosis. Although there is little data on acute abdominal pain in children suspected of having Covid-19, even those few studies refer to a frequent incidence of abdominal pain in children who test positive for Covid-19.

In a prospective study conducted in the UK, it turns out that half of the children who tested positive for Covid-19 were asymptomatic, but of the children who had concerns about 19\% complained of gastrointestinal problems [4].

Latest findings from the Covid-19 Symptom Study app, [5] which was launched in late March to track people's symptoms, also show that gastrointestinal symptoms occur frequently in children with positive swab tests.[56]

\section{Conclusion:}

While the Covid-19 pandemic is rapidly spreading and not sparing even children, pediatricians and surgeons must be very cautious in treating children with acute abdominal pain since infections with Covid-19, and not surgical diseases, might be the real cause of these concerns.

\section{Reference}

1. World Health Organization. Statement on the second meeting of the International Health Regulations. Emergency Committee regarding the outbreak of novel coronavirus (2019-nCoV) 2005. [Accessed 14 February 2020]. Available from: https://www.who.int/news-room/detail/30-01-2020statement-on-the-second-meeting-of-the-international-healthregulations-(2005)-emergency-committee-regarding-theoutbreak-of-novel-coronavirus-(2019-ncov)

2. Song Y, Liu P, Shi XL, Chu YL, Zhang J, Xia J, et al. SARS-CoV-2 induced diarrhoea as onset symptom in patient with COVID-19. Gut. 2020 Mar 5; doi: 10.1136/ gutjnl-2020-320891. pii: gutjnl-2020-320891. [PubMed] [CrossRef] [Google Scholar]

3. Liang W, Feng Z, Rao S, Xiao C, Xue X, Lin Z, et al. Diarrhoea may be underestimated: a missing link in 2019 novel coronavirus. Gut. 2020 Feb 26; doi: 10.1136/ gutjnl-2020-320832. pii: gutjnl-2020-320832. [PubMed] [CrossRef] [Google Scholar]

4. Waterfield T, Watson C, Moore R, et al. Seroprevalence of SARS-CoV-2 antibodies in children: a prospective multicentre cohort study. medRxiv 2020.08.31.20183095 [Preprint]. 2 September 2020. www.medrxiv.org/ content/10.1101/2020.08.31.20183095v1.

5. Covid Symptom Study. https://covid.joinzoe.com/data.Google Scholar

6. Mayor S. Covid-19: Researchers launch app to track spread of symptoms in then UK. BMJ2020;368:m1263. doi:10.1136/ bmj.m1263 pmid:32220898 